\title{
ESTIMATION OF SATURATION FLOW OF HETEROGENEOUS TRAFFIC USING COMPUTER SIMULATION
}

\author{
Prof. Dr. V. Thamizh Arasan \& \\ P. Vedagiri \\ Transportation Engineering Division, Department of Civil Engineering, \\ Indian Institute of Technology Madras, Chennai, 600 036, India. \\ E.mail: arasan@iitm.ac.in
}

\section{KEY WORDS}

Heterogeneous Traffic, Simulation, Saturation Flow.

\begin{abstract}
The road traffic in developing countries like India are highly heterogeneous with vehicles of wide ranging static and dynamic characteristics. The heterogeneous traffic do not follow traffic lanes and hence, the available models of traffic flow, which are based on lane based homogeneous traffic, can not be applied to study the characteristics of heterogeneous traffic flow. Recently, a simulation model named, HETEROSIM has been developed to replicate the field conditions of heterogeneous traffic flow. This paper is concerned with application of the model to estimate the saturation flow rate of heterogeneous traffic with the specific purpose of studying the effect of road width on saturation flow measured in passenger car units (PCU) per unit width of road.
\end{abstract}

\section{INTRODUCTION}

The term saturation flow is defined as the maximum rate of flow that can pass through a given road space (width), under prevailing roadway and traffic conditions, during the effective green time in a signal phase. Saturation flow is an important input parameter in the design of cycle time for traffic signals. Hence, it is necessary to have information on saturation flow for various roadway and traffic conditions to provide appropriate input for signal design without resorting to field measurement. The information on saturation flow can be generated for any given roadway and traffic conditions, if a model of road-traffic flow is available. Over the resent decades, with the availability of simulation technique, the modeling of road traffic flow has attained a high level of perfection.

Computer simulation is a valuable tool for the analysis and design of complex transportation systems. Simulation models may be classified as being static or dynamic, deterministic or stochastic, and discrete or continuous. A simulation model, which does not require any random values as input, are generally called as deterministic, whereas a stochastic simulation model has one or more random variables as inputs. Random inputs lead to random outputs and these can only be considered as estimates of the true characteristics of the system being modeled. Discrete and continuous models are defined in an analogous manner. The choice of whether to use a discrete or continuous simulation model is a function of the characteristics of the system and the objectives of the study (Banks et al. 2004). For this study, a dynamic stochastic type discrete event (continuous traffic flow split over one second time intervals to resemble discrete events) simulation is adopted in which the aspects of interest are analysed numerically with the aid of a computer program.

Modelers often try to describe simulation models as being microscopic, mesoscopic, or macroscopic. The difference pertains mainly to the level at which the traffic flow phenomena are being represented. Microscopic models capture the movement of every vehicle. They contain processing logic, which describes how vehicles behave. This description includes acceleration, deceleration, lane changes, passing maneuvers, turning-movement execution, and gap acceptance. Macroscopic models are at the other end of the spectrum. They tend to employ flow rate variables and other general descriptors of how the traffic is moving. Mesoscopic models fall in between. They typically model the movement of clusters or platoons of vehicles and incorporate equations that indicate how these clusters of vehicles interact. This paper is concerned with the development of micro simulation model of heterogeneous traffic and application of the model to estimate the saturation flow rate.

\section{SIMULATION FRAMEWORK}

This study pertains to the traffic conditions prevailing in India. The road traffic in India is highly heterogeneous comprising vehicles of wide ranging static and dynamic characteristics and all the vehicle share the same road space. Smaller vehicles like motorized two-wheeler and bicycle are predominant and these share the same road space (without segregation) with other larger vehicles. Hence, there is difficulty in imposing lane discipline under such conditions and the vehicles occupy any lateral position on the road depending on the availability of space at a particular instant. As the available traffic simulation models are based on homogeneous traffic conditions, where clear lane and queue discipline exists, 
it is not possible to apply the models to study the heterogeneous traffic flow characteristics. Also, the research attempts made to model heterogeneous traffic flow (e.g- Katti and Ragavachari 1986; Marwah 1995; Kumar and Rao 1996; Khan and Maini 2000) are limited in the scope and do not address all the aspects comprehensively. Hence, there was a need to develop appropriate models to simulate the heterogeneous traffic flow. Accordingly a model of heterogeneous traffic flow, named, HETEROSIM was developed (Arasan and Koshy 2005). The modeling framework is explained briefly here to provide the background for the study. For the purpose of simulation, the entire road space is considered as single unit and the vehicles are represented as rectangular blocks on the road space, the length and breadth of the blocks representing respectively, the overall length and the overall breadth of the vehicles. The front left corner of the rectangular block is taken as the reference point, and the position of vehicles on the road space is identified based on the coordinates of the reference point with respect to an origin chosen at a convenient location on the space. The simulation model uses the interval scanning technique with fixed increment of time. For the purpose of simulation, the length of road stretch as well as the road width can be varied as per user specification. The model was implemented in $C++$ programming language with modular software design. The flow diagram illustrating the basic logical aspects involved in the program is shown as Fig. 1. It can be seen that the first vehicle is generated after initialization of the various parameters required to simulate heterogeneous traffic flow. Then, the generated vehicle is added to the system when the current time (clock time) becomes equal to the cumulative headway. At this stage, the module for adding vehicles ("Add Vehicle") will be activated to facilitate the process. At higher traffic-flow levels, there is a chance of more vehicle arrivals during each scan interval (taken as one second in this case). To address this aspect, an additional clock for scanning with a precision of $0.05 \mathrm{~s}$ was provided. Checking for the possibility of placing a generated vehicle during a scan interval on the simulation road stretch, as well as updating the status of the vehicles already in the system are done when the cumulative precision scan interval is equal to the set scan interval of $1 \mathrm{~s}$. The program also facilitates immediate addition of each of the generated headways to the output file. The simulation is

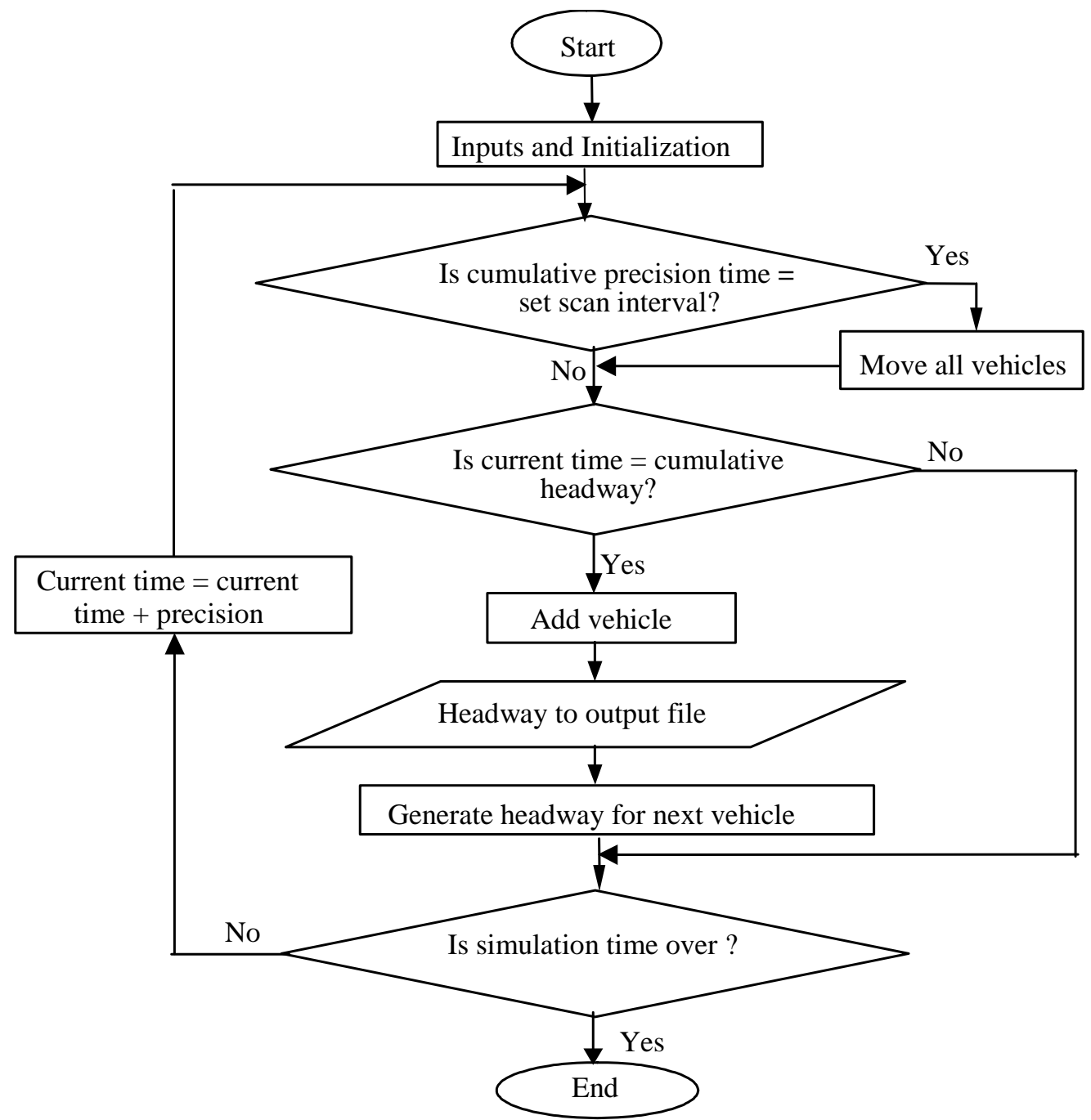

Figure1: Flow Diagram for Simulation Model 
continued until the input simulation run- length is completed.

The simulation model is also capable of replicating the traffic flow through signalized intersections for various signal settings. Modeling this aspect is some what complicated because the model should be able to simulate any possible mix of traffic movements and for any given value of cycle time. In the computer program, an array of integers was found to be suitable to store the details of signal settings [Array is a data type consisting of a group of numerical values of similar kind]. This array consists of the starting times of red, green, and amber durations of different directional traffic movements (left, straight, and right) on different approaches. In each scan interval, the clock time is compared with the values of the array and the status of the signal is updated accordingly. This clock time is different from the original clock time of the simulation, wherein the time goes on increasing as the simulation continues. The clock time pertaining to the signal settings, however, will be brought to zero when the clock time equals the cycle time. So, at any instant of time, the clock time in this module takes values ranging from zero to cycle time.

The model is also capable of displaying the animation of simulated traffic movements through the intersection. The animation module of the simulation model displays the model's operational behavior graphically during the simulation runs. It is a useful tool for validation of the model, and helps to study the changes in the behavior of the system when various input parameters are changed. The input required for the model to simulate the heterogeneous traffic flow are: road geometry, details of signal settings, traffic volume and composition for the different stream of traffic approaching the intersection, vehicle dimensions, minimum and maximum lateral spacing between vehicles, and free speeds, acceleration and deceleration of vehicles. Speed, volume, delay, overtaking, etc., of individual vehicles and the whole of the traffic are the possible output of the model.

\section{MODEL VALIDATION}

Validation is the process of comparing model results with the corresponding field observed values to ensure that such results realistically represent the real system. Only measurable data from the field can be used to validate model results. Though the available model is generally validated, it was decided to check for the appropriateness of the model for the specific requirements of this study. Accordingly the model was validated for its ability to replicate saturation flow conditions. The data input required for model validation can be broadly divided into two types, namely, the data of individual vehicles and the roadway and traffic data. The different types of vehicles on the city roads of India can be grouped into nine types as (i) Bus, (ii) Truck, (iii) Light Commercial Vehicle (LCV) - large passenger vans and small trucks, (iv) Cars - cars, jeeps and small passenger vans,(v) Motorized Three-Wheeler (M.Th.W) - three wheeled motorized vehicles to carry a maximum of three passengers or small quantities of goods, (vi) Motorized Two-Wheeler (M.T.W)-motor cycles, scooters and mopeds, (vii) Bicycle, (viii) Tricycle three wheeled pedal-type vehicle to carry a maximum of two passengers or small quantities of goods, (ix) Animal Drawn Vehicles (A.D.V)-carts drawn by bullock/horse/camel. The relevant characteristics of the vehicles are given in Table1.

\section{Study Intersection}

Since the objective of the study is to estimate the saturation flow, an approach to a signalized intersection was considered for model validation. The signalized junction of Senatoph Road with Anna Salai in the southern part of Chennai city in India was considered for the purpose. The approach on the southern leg of the junction (falling on Anna Salai) was $12.5 \mathrm{~m}$ wide and the whole of traffic on the approach has only straight on movement (Fig 2). The signal cycle time (evening peak) is 180 seconds and the actual green time available for the traffic on the study approach was 55 seconds. The saturation flow of traffic on the study approach was measured in the field by making a classified count of all

Table 1: Characteristics of Vehicles of the Heterogeneous Traffic

\begin{tabular}{|c|c|c|c|c|c|c|}
\hline \multirow{2}{*}{$\begin{array}{c}\text { Vehicle Type } \\
\text { (1) }\end{array}$} & \multicolumn{2}{|c|}{ Dimensions in $\mathrm{m}$} & \multicolumn{2}{|c|}{ Lateral Clearances in m } & \multirow{2}{*}{$\begin{array}{c}\text { Mean Free Speed } \\
\text { in } \mathrm{Km} / \mathrm{hr} \\
(6)\end{array}$} & \multirow{2}{*}{$\begin{array}{l}\text { PCU } \\
\text { Value } \\
(7)\end{array}$} \\
\hline & $\begin{array}{l}\text { Length } \\
\text { (2) }\end{array}$ & $\begin{array}{l}\text { Breadth } \\
\text { (3) }\end{array}$ & $\begin{array}{l}\text { Minimum } \\
\text { (4) }\end{array}$ & $\begin{array}{l}\text { Maximum } \\
\text { (5) }\end{array}$ & & \\
\hline Bus & 10.3 & 2.5 & 0.3 & 0.6 & 53 & 2.5 \\
\hline Truck & 7.5 & 2.5 & 0.3 & 0.6 & 51 & 2.5 \\
\hline Light Commercial Vehicle & 5.2 & 2.0 & 0.3 & 0.5 & 48 & 1.2 \\
\hline Car & 4.0 & 1.6 & 0.3 & 0.5 & 60 & 1.0 \\
\hline Motorized Three Wheeler & 2.6 & 1.4 & 0.2 & 0.4 & 45 & 0.6 \\
\hline Motorized Two Wheeler & 1.8 & 0.6 & 0.1 & 0.3 & 48 & 0.35 \\
\hline Bicycle & 1.9 & 0.5 & 0.1 & 0.3 & 14 & 0.3 \\
\hline Tricycle & 2.5 & 1.3 & 0.1 & 0.3 & 12 & 1.2 \\
\hline
\end{tabular}

Note: 1. Animal Drawn vehicles were not present on the study stretch.

2. The Minimum Clearance value pertains to zero speed condition and the maximum Clearance corresponds to a speeds of $60 \mathrm{kmph}$ and more. The clearance value is assumed to vary linearly from minimum to maximum depending upon the speed of vehicles.

3. Lateral clearance is the clearance share pertaining to a vehicle type. For example, if a bus and M.Th.W. are located side by side. The minimum lateral clearance between the two vehicles will be $0.3+0.2=0.5 \mathrm{~m}$ 
the vehicles crossing the stop line (when the signal is green) while the moving bunch of vehicles moved continuously without break and the counting was stopped soon after a break is observed in the bunch of vehicles on the approach. Care was also taken not to count the vehicles in the first five seconds of the green time to allow for the starting delay of vehicles at the front. A total of thirty such observations were made to provide adequate database for validation. The traffic data, as observed in the field, is shown in Table 2. While observing the saturation flow in the field, it was found that the number of tricycles in the traffic stream was negligible about $(0.1 \%)$. Hence, each tricycle was considered to be equivalent to two bicycles and included in the counting of bicycles.

\section{Simulation}

For validating the simulation model the traffic flow through the signalized junction was first simulated.
Based on a recent traffic study conducted at the Junction (Suhas, 2005), for the purpose of vehicle generation and placement in the simulation process, the inter arrival time of vehicles was assumed to follow negative Exponential distribution and the free speed of vehicles was assumed to follow Normal distribution. The observed traffic composition was given as input to the simulation model. The simulated saturation flow on the study approach (involving only straight-on traffic flow) was recorded for 30 signal cycles. Since the saturation flow is influenced only by the road width and traffic composition, each of the approaching roads can be considered independently without consideration to the total traffic flow through the whole of the intersection. For this purpose, for each simulated signal cycles, the number of vehicles crossing the stop line of the study approach, starting from the $5^{\text {th }}$ second from the start of the green for the approach to the time at which the continuity in the bunch of vehicles on the

Table 2: Saturation Flow of Traffic on the Study Approach to the Signalized Intersection

\begin{tabular}{|c|c|c|c|c|c|c|c|c|}
\hline \multirow{2}{*}{$\begin{array}{l}\text { Signal } \\
\text { Cycle. } \\
\text { Number. } \\
\text { (1) }\end{array}$} & \multirow{2}{*}{$\begin{array}{l}\text { Saturated } \\
\text { Green Time } \\
\text { (sec.) } \\
\\
\text { (2) }\end{array}$} & \multicolumn{7}{|c|}{ Number of Vehicles Crossing the Stop Line During Saturated Green Time } \\
\hline & & $\begin{array}{l}\text { Bus } \\
\text { (3) }\end{array}$ & $\begin{array}{l}\text { Truck } \\
\text { (4) }\end{array}$ & $\begin{array}{c}\text { Light } \\
\text { Commercial } \\
\text { Vehicle } \\
(5)\end{array}$ & $\begin{array}{l}\text { Car } \\
\text { (6) }\end{array}$ & $\begin{array}{c}\text { Motorized } \\
\text { Three - } \\
\text { Wheeler } \\
\text { (7) }\end{array}$ & $\begin{array}{c}\text { Motorized } \\
\text { Two - } \\
\text { Wheeler } \\
(8)\end{array}$ & $\begin{array}{c}\text { Bicycle } \\
\text { (9) }\end{array}$ \\
\hline 1 & 56 & 9 & 1 & 5 & 54 & 33 & 90 & 8 \\
\hline 2 & 40 & 2 & 1 & 7 & 40 & 27 & 67 & 9 \\
\hline 3 & 38 & 3 & 1 & 6 & 23 & 21 & 77 & 4 \\
\hline 4 & 23 & 4 & 2 & 4 & 12 & 15 & 28 & 2 \\
\hline 5 & 48 & 7 & 3 & 3 & 26 & 25 & 40 & 3 \\
\hline 6 & 51 & 6 & 4 & 4 & 27 & 24 & 60 & 7 \\
\hline 7 & 34 & 7 & 2 & 3 & 24 & 17 & 37 & 2 \\
\hline 8 & 20 & 2 & 2 & 2 & 8 & 8 & 25 & 1 \\
\hline 9 & 44 & 4 & 2 & 2 & 42 & 17 & 53 & 4 \\
\hline 10 & 20 & 3 & 2 & 5 & 18 & 6 & 20 & 2 \\
\hline 11 & 56 & 8 & 1 & 2 & 55 & 31 & 87 & 10 \\
\hline 12 & 43 & 4 & 2 & 3 & 38 & 25 & 65 & 8 \\
\hline 13 & 37 & 5 & 2 & 4 & 25 & 23 & 79 & 5 \\
\hline 14 & 23 & 6 & 1 & 5 & 10 & 17 & 26 & 4 \\
\hline 15 & 43 & 4 & 2 & 4 & 28 & 23 & 38 & 2 \\
\hline 16 & 38 & 3 & 3 & 8 & 23 & 20 & 63 & 8 \\
\hline 17 & 34 & 4 & 4 & 3 & 29 & 21 & 40 & 3 \\
\hline 18 & 21 & 3 & 2 & 4 & 10 & 10 & 25 & 6 \\
\hline 19 & 48 & 2 & 3 & 7 & 39 & 15 & 48 & 2 \\
\hline 20 & 25 & 2 & 3 & 2 & 20 & 9 & 25 & 1 \\
\hline 21 & 57 & 5 & 0 & 4 & 50 & 30 & 81 & 5 \\
\hline 22 & 43 & 2 & 1 & 3 & 42 & 24 & 65 & 4 \\
\hline 23 & 35 & 3 & 0 & 8 & 26 & 25 & 80 & 3 \\
\hline 24 & 24 & 4 & 1 & 4 & 15 & 14 & 25 & 1 \\
\hline 25 & 47 & 5 & 2 & 5 & 23 & 23 & 44 & 2 \\
\hline 26 & 50 & 4 & 3 & 6 & 24 & 28 & 61 & 6 \\
\hline 27 & 34 & 8 & 4 & 4 & 20 & 19 & 39 & 5 \\
\hline 28 & 21 & 3 & 1 & 5 & 10 & 10 & 21 & 2 \\
\hline 29 & 47 & 4 & 2 & 3 & 39 & 18 & 53 & 5 \\
\hline 30 & 25 & 3 & 2 & 2 & 15 & 8 & 20 & 2 \\
\hline Total & 1125 & 129 & 59 & 127 & 815 & 586 & 1482 & 136 \\
\hline
\end{tabular}




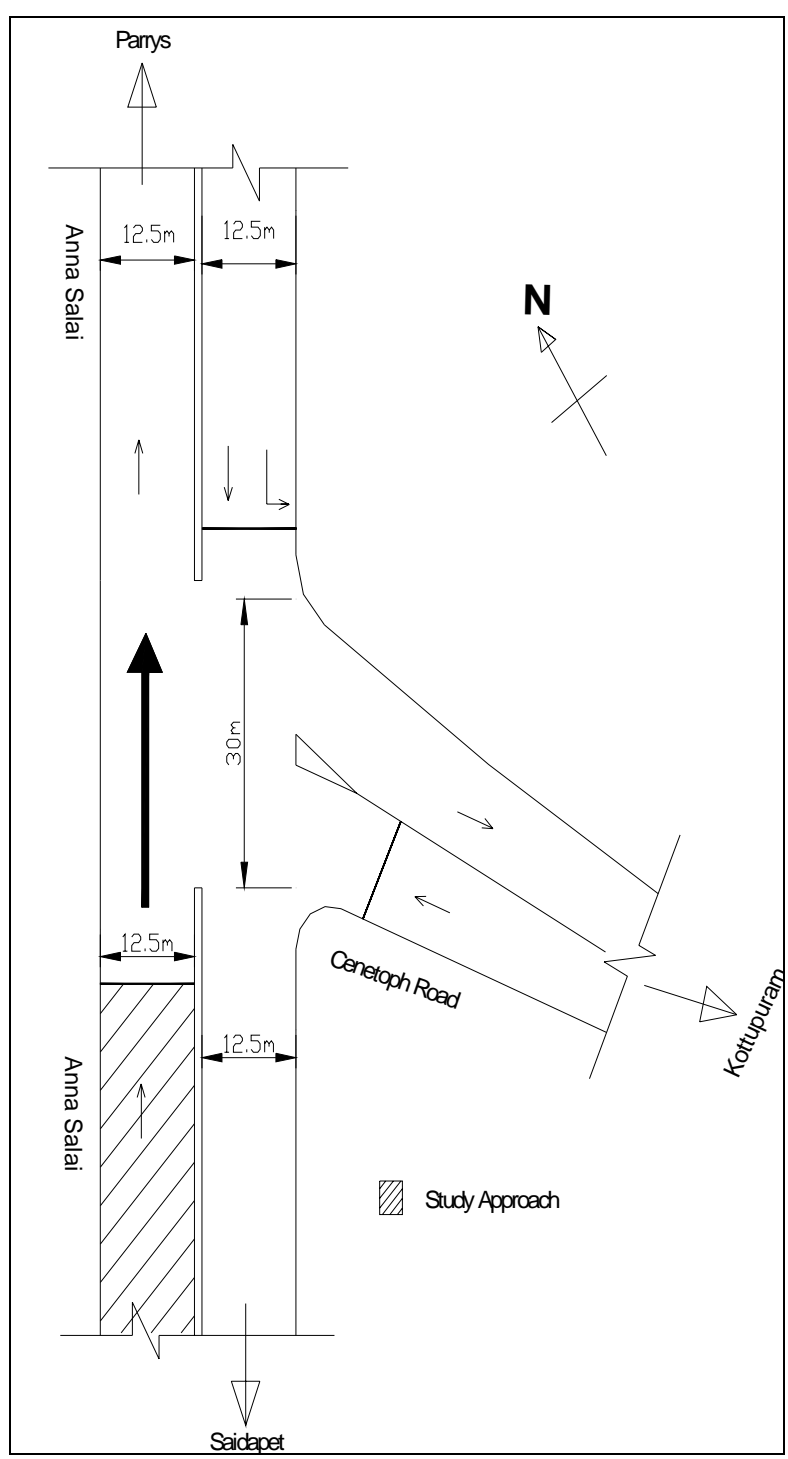

Figure 2: Study Intersection

approach breaks were counted. The classified count of all the vehicles during the time period was done automatically by partitioning the time period pertaining to the approach from the overall simulation process. The simulation runs were made with three random number seeds and the averages of the three values were taken as the final model output. Then, a comparison of the observed and simulated saturation flow rates was made by comparing the total number of vehicles in each category crossing the stop line for the total saturated green time ( total of the 30 observations) of 1125 seconds. The details of the comparison, along with the percentage error, are shown in Table 3 . It can be seen that the error is within acceptable limits considering the fact the system being simulated is highly complex involving vehicles of wide ranging static and dynamic characteristics.

\section{MODEL APPLICATION}

The validated model was then applied to study the effect of road width on saturation flow rate of the
Table 3: Comparison of Observed and Simulated Saturation Flow of Vehicles

\begin{tabular}{|c|c|c|c|}
\hline \multirow{2}{*}{$\begin{array}{c}\text { Vehicle } \\
\text { Type }\end{array}$} & \multicolumn{2}{|c|}{$\begin{array}{c}\text { Number of Vehicles } \\
\text { Crossing the Stop Line* }\end{array}$} & $\begin{array}{c}\text { Percentage } \\
\text { Error }\end{array}$ \\
\cline { 2 - 3 }$(1)$ & $\begin{array}{c}\text { Observed } \\
(2)\end{array}$ & $\begin{array}{c}\text { Simulated } \\
(3)\end{array}$ & $(4)$ \\
\hline Bus & 129 & 113 & 12.4 \\
\hline Truck & 59 & 63 & -6.8 \\
\hline LCV & 127 & 137 & -7.9 \\
\hline Car & 815 & 784 & 3.8 \\
\hline M. Th.W & 586 & 545 & 6.9 \\
\hline M. T.W & 1482 & 1372 & 7.4 \\
\hline Bicycle & 126 & 116 & 7.9 \\
\hline $\begin{array}{c}\text { Total of } \\
\text { all } \\
\text { vehicles }\end{array}$ & 3324 & 3130 & 5.8 \\
\hline
\end{tabular}

* Note: The comparison is based on a total saturated green time of 1125 Seconds.

LCV- Light Commercial Vehicle,M. Th.W -Motorized Three Wheeler M. T.W -Motorised Two Wheeler

heterogeneous traffic. For this purpose, a typical four legged signalized intersection was considered and the traffic flow through the intersection was simulated for various widths of approaches. The signal settings and the traffic- volume input were adjusted for each case in such a way that is at least 50 seconds of saturated green time was available in the signal phase pertaining to the study approach. A representative traffic composition (prevailing on most major roads of the cities in India) was considered (Fig .3) for the purpose of simulation.

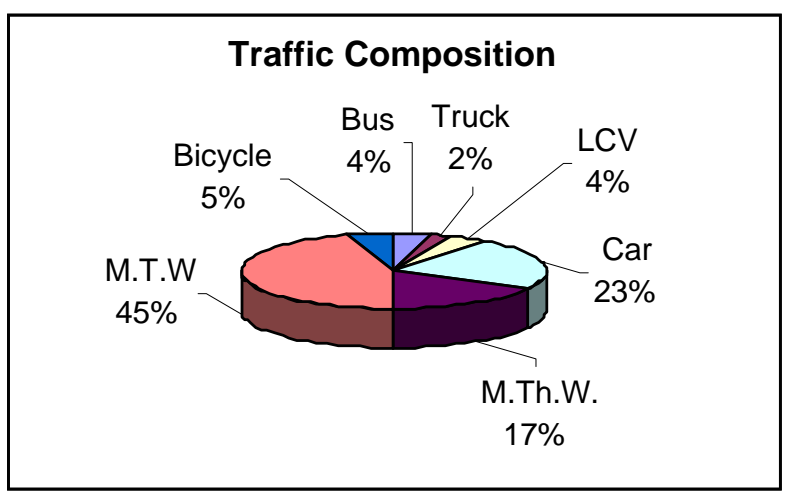

Figure 3: Traffic Composition Considered for Simulation

LCV- Light Commercial Vehicle, M. Th.W. -Motorized Three Wheeler, M. T.W. -Motorised Two Wheeler

The saturation flow was measured using simulation as per the procedure explained under the section 'Model Validation'. A total of 7 alternative widths of approach were considered and the saturation flow estimated for each case. The saturation flows, expressed in number of the different categories of vehicles, were converted into equivalent passenger car units (PCU) using the PCU values given in column (7) of Table 1, which was arrived at through an earlier study (Arasan and 
Jagadeesh 1995). Because of laneless traffic flow condition, the saturation flow could not be expressed as flow per traffic lane and hence, was expressed as flow per unit width of road way (PCU per metre width ).Then a plot was made relating the approach widths in $\mathrm{m}$ and the saturation flow in PCU/m (Fig .4).

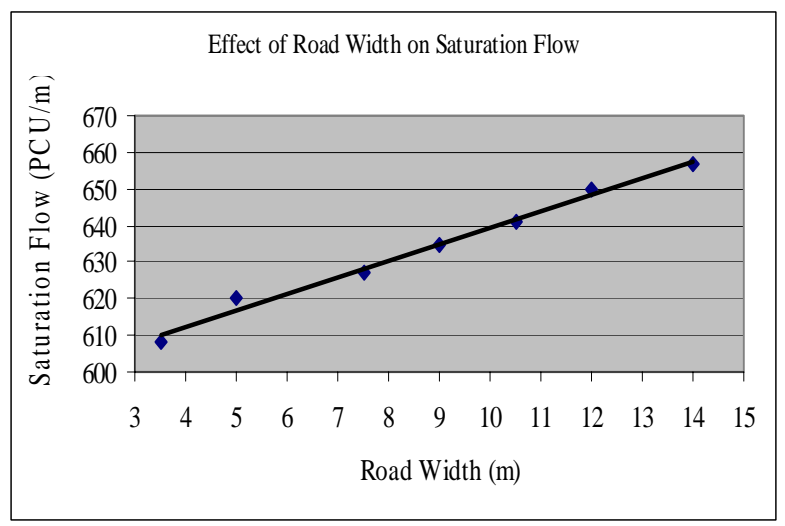

Figure 4: Effect of Road Width on Saturation Flow Rate

It can be understood from the figure that the saturation flow rate per unit width of approach marginally increases with increase in the width of approach. The reason for the increase in saturation flow rate per metre width with increase in width of approach, may be attributed to the fact that the vehicles of heterogeneous traffic with wide variations in their over all dimensions, are able to more and more effectively make use of the road space, under saturated conditions, as the width of the road increases.

\section{CONCLUDING REMARKS}

Through this study, it has been established that the software package HETEROSIM, developed to model heterogeneous traffic flow can be effectively used to estimate saturation flow rates for various roadway and traffic conditions prevailing in developing countries like India. It has been found that under heterogeneous traffic conditions, there is a significant increase in the saturation flow rate (measured in PCU per meter width) with increase in the width of approach road. The study reported here is limited to estimation of saturation flow rate of straight-on traffic only and the authors currently are involved in application of the simulation technique to estimate saturation flow of turning traffic streams of heterogeneous traffic.

\section{REFERENCES}

Arasan,V.T. and K.Jagadeesh. 1995. "Effect of Heterogeneity of Traffic on Delay at Signalised Intersections". Journal of Transportation Engineering, ASCE Vol. 121 No.5, 398-404.

Arasan, V. T. and R. Z. Koshy. 2005. "Methodology for Modelling Highly Heterogeneous Traffic Flow”. Journal of Transportation Engineering, ASCE Vol. 131 No.7, 544 -551 .
Banks, J.; J.S.Carson; L.N. Barry; and M.N. David. 2004. Discrete-Event System Simulation. Pearson Education, Singapore, Third Edition , 12-14.

Katti, V.K. and S.Raghavachari. 1986. "Modeling of Mixed Traffic with Speed Data as Inputs for the Traffic Simulation Models". Highway Research Bulletin, 28, Indian Roads Congress, 35-48.

Khan, S.I. and P.Maini. 2000. "Modeling Heterogeneous Traffic Flow". Transportation Research Record, 1678, Transportation Research Board, Washinton,D.C,234- 241.

Kumar, V.M and S.K. Rao. 1996. "Simulation Modeling of Traffic Operations on Two- lane Highways". Highway Research Bulletin, 54, Indian Roads Congress, 211-137.

Marwah, B.R. 1995. "Simulation and Animation of Traffic Flow on Highways with Intersections". International Conference on New Horizons in Road and Road Transport, Roorkee, 989-999.

Suhas B.K. 2005. "Time Space Allocation to Maximize Heterogeneous Traffic Flow Through Signalized Intersections". Masters Thesis, Transportation Engineering Division, Department of Civil Engineering, Indian Institute of Technology Madars, Chennai, India.

\section{AUTHOR BIOGRAPHIES}

Prof. Dr. V. Thamizh Arasan is currently a full Professor in the Transportation Engineering Division of the Department of Civil Engineering of Indian Institute of Technology Madras, Chennai, India, which is one of the seven national level higher technological institutions in the country. He has a professional experience of about 25 years in teaching research and consultancy in the area of Transportation Engineering. Travel demand modeling and traffic flow modeling are his areas of research interest. He has guided a number of doctoral degree students and has published more than sixty research papers in international and national journals and conference proceedings. Two of his papers published in journals have received awards for excellence in research. Prof. Arasan has successfully completed several sponsored research projects both at national and international levels. The international projects are: (i) on Development of Transportation Planning Techniques for Indian conditions in collaboration with the Technical University of Braunschweig, Germany and (ii) on Enhancing the Level of Safety at Traffic Signals in collaboration with the Technical University of Darmstadt, Germany. Prof. Arasan is member of several professional bodies and Technical committees of Government departments.

Mr. P.Vedagiri is a Ph.D. Scholar in Transportation Engineering Division, Department of Civil Engineering, Indian Institute of Technology Madras, Chennai, India. His doctoral research work is in the area of 'Heterogeneous Traffic Flow Modeling'. Mr. Vedagiri obtained his undergraduate degree in the area of Civil Engineering in the year 2002 and post graduate degree in the area of Urban Engineering in the year 2004 from Anna University, Chennai, India. He is interested in teaching and wishes to pursue an academic career on completion of his doctoral work. 